Hajjath, A.K.M. and Rathnayake, M.D., 2019. Appropriateness of CIDA price fluctuation formula for road construction in Sri Lanka. In: Sandanayake, Y.G., Gunatilake, S. and Waidyasekara, A. (eds). Proceedings of the $8^{\text {th }}$ World Construction Symposium, Colombo, Sri Lanka, 8-10 November 2019, pp. 107-115. DOI: doi.org/10.31705/WCS.2019.11. Available at: https://2019.ciobwcs.com/papers

\title{
APPROPRIATENESS OF CIDA PRICE FLUCTUATION FORMULA FOR ROAD CONSTRUCTION IN SRI LANKA
}

\author{
A.K.M. Hajjath ${ }^{1}$ and M.D. Rathnayake ${ }^{2}$
}

\begin{abstract}
The use of the construction industry development authority (CIDA) formula of price fluctuation will help to claim unpredicted costs in construction projects at least up to a satisfying level. However, some limitations were made when preparing the formula to ease the calculation. Therefore, the project aims to find out the factors affecting the CIDA price fluctuation formula and to identify the appropriate use of the CIDA price fluctuation formula for road construction. A mixed approach was utilized for the study. A broad study of the literature review was intended to a price fluctuation concept and price fluctuation reclamation methods and the significance of road construction projects. The semi-structured and structured close-ended questionnaires were carried out to collect data to identify issues and factors affecting the formula. The qualitative data were analyzed through Qualitative Data Analysis (QDA) Miner lite software while quantitative data were analyzed through SPSS software. A framework was developed concerning outcomes. The price indices, coefficient (0.966), input percentage of construction inputs were found as internal factors which are affecting the formula with their issues and also the difficulties faced while calculation of those internal factors, type of the contract, assumptions which are used to make the formula were found as the external factors. This framework can be recommended to use as a tool before commencing the price fluctuation calculation using the CIDA formula for understanding which factors are mostly helping to increase the appropriateness of the CIDA formula in the road construction sector.
\end{abstract}

Keywords: CIDA Price Fluctuation Formula; Price Fluctuation; Road Construction Project.

\section{INTRODUCTION}

Due to its standard, easiness and High obtainability of information, the CIDA formula was the most popular and commonly used method in the Sri Lankan construction industry (Dilshani and Disaratna, 2014). According to Dilshani and Disaratna, (2014) the increase or decrease in construction costs was calculated using price indices under a contract of price fluctuation. Generally, the rise or fall in the price of goods, materials, and services was defined as price fluctuation (Mishra and Regmi, 2017). According to Mishra and Regmi (2017), if a contractor bids at a fixed price will face the risk that his payment for material and labor may increase more than the price which was agreed at the tender stage.

\footnotetext{
${ }^{1}$ Department of Quantity Surveying, University College of Anuradhapura, University of Vocational Technology, Sri Lanka, qshajjath@gmail.com

2 Department of Quantity Surveying, University College of Anuradhapura, University of Vocational Technology, Sri Lanka, muviniqs@gmail.com
} 
The price of construction inputs can be increased because of the following reasons; disasters by nature, construction demand was increased, rise in rate, and rise in fuel prices (Silva, 2011). The escalation clauses in the contract can be practiced even on average and below-average size constructions because of the changes in the economy due to the prices of gas and oil (Rodriguez, 2018).

The constitution of road construction is a major part of the construction industry for developing the economy of the nation (Kaliba et al, 2008). Price fluctuation in the various inputs and the type of project effects the cost escalation factors in between $3.5 \%<\mathrm{X}<7$ $\%$ in Transportation projects (Raniga, 2015). According to the Construction Industry Council (2011), by comparing other countries' price fluctuation adjustment practices, it says that a single formula not fits all rules and regulations and also can't satisfy the construction main stakeholders. In Sri Lanka, the price fluctuations were calculated by using formula and traditional methods (Liyanage, 2005). According to Ranathunge (2010), the formula method has an easy and quick process of price fluctuation calculation than the traditional method (As cited at Jayaweera et al, 2015). It is better to use the CIDA price fluctuation formula for projects which have lots of work items and gets a longer duration than the traditional method because it is a boring and lengthy task (Jayalath, 2013). According to Jayalath, (2013) the simplified CIDA formula was appropriate for small contracts that have a minor number of works. In another place of his research Jayalath, (2013) stated that the government was approved to use the formula method for price fluctuation compensation and the use of formula method acts as a pointed rule for government projects. The Procurement Guidelines (2006) states that the price fluctuation formula should be inserted in the bidding document as well as in the contract agreement for the Sri Lankan money for construction contracts which have more than 3 months' duration.

The aim of the research is to find out the factors affecting the CIDA formula in road construction and to suggest an appropriate use of the CIDA formula for the construction of roads.

\section{LITERATURE REVIEW}

Price escalation refers that, the goods and services that have changed over an economic period in their cost or price (Jayasinghe et al, 2015). There was an unstable situation in price fluctuation that it was very tough to expect what may be the price of a tender (Douglas, 2010). The contractors were failed to complete their projects within the agreed period and qualify for the client when the prices of construction inputs have been increased (Mishra and Regmi, 2017). World over the necessities of price adjustment as a result of a fluctuation in prices of construction inputs was practiced to prepare bids at the maximum level of accuracy and also to complete the contracts on an even-handed and simply manner (PECI, 2009). Price adjustment provisions/ clauses are included formulas designed to address problems to protect both the borrower and contractors from price fluctuations by allowing contractors to offer more realistic prices at the time of bidding (Asian Development Bank, 2018). CIDA (2007) states the provisions of the price fluctuation under the clause number 13.7, which was titled as "Adjustment for Changes in Cost (in construction)" and also the price fluctuation amount due to the changes in cost of the construction inputs like labour, material and machinery or plant, which was calculated using the formula mentioned in the clause should be added or deducted in contractors' payment. The Procurement Guidelines (2006) states that the price fluctuation 
formula should be inserted in the bidding document as well as in the contract agreement for the Sri Lankan money for construction contracts which have more than 3 months' duration. For such cases, it is better to go with the CIDA formula even though other recovery methods can be used for price fluctuation calculation (Jayaweera et al, 2015.)

\subsection{ReAsons FOR FLUCTUATION In PRICE OF CONSTRUCTION INPUTS}

An increase in the price of oil in the world market and a new era in technology and a rise in price are some reasons which fluctuate the cost of goods and services (Sendooran, 2005). Even though the country's economy and political issues are cause the fluctuations in the price of oil, the OPEC (Organisation of the Petroleum Exporting Countries) has major constitution in oil price not only that but also the factors of basic demand and supply, costs for production, and percentage of interest (Lioudis, 2018). Hanna and Blair (1993) say that the basic factors which cause the fluctuation in price are the current situation of the market, rise in the price of inputs, Government policies, duties, and political impacts.

\subsection{ImPaCt OF Price FluCtuation in Construction Contracts}

Numerous aspects impact the construction project costs like changes in the scope of the project, unpredictable estimation of the project cost, Instruction changes, an extension of time or duration, and the lengthy design stage. But it is essential to consider volatility, not only because of causing price escalations but because of fluctuation in price affects the allocation of resources and decisions which are making for selecting the project (Macdonald, 2013). The difference between final project cost and the initial estimated cost was defined as construction cost escalation (Dawood et al., 2001). Changes in material prices are one of the primary factors which cause the construction cost escalation (Moynihan and Al-Zarrad, 2015). These price increases in construction inputs give rise to entitlements, cost escalation, shortage in housing supply causing in a great cost of urban housing scheme, losing quality in estimation process quickly, difficult to plan a project and also to estimate it, and regular price fluctuation in contracts, as a whole it leads to termination of the project (Nwuba, 2004).

\subsection{Price Fluctuation Recovery Methods Practiced by the CONSTRUCTION INDUSTRY}

According to Liyanage (2005), the parties in construction are using two methods in order to compensate in a contract for fluctuations, i.e. through traditional method the actual cost was paid for the contractor which incurred due to price fluctuation, and through formula method, reliant on the value of work done the contractor was paid for price fluctuation. The contractor was provided with a list of the major inputs like materials, labour, and plant and machinery which will be used in the construction at the time of tender and based on the rates in bill the prices per unit for those inputs will be inserted according to the conventional method (Jayasinghe et al, 2015). Suraweera (2001) states that the losses due to cost escalation will compensate by the amount in the contract which was calculated by the formula method and there should be some differences between the usage of formula and traditional methods with the level of recovery. 


\subsection{CIDA Formula METHOD FOR PRICE FLUCTUATION}

The contracts in Sri Lanka are administered by the Construction Industry Development Authority (CIDA) of our Country by maintaining the quality of state's-specific documents (Jayalath, 2013). Price fluctuation recovery using formula method is calculating fluctuation amount in a contract by offering a realistic origin for calculation. Project values more than ten million can use the formula method for the contract and it is appropriate for price fluctuation costs inside the nation (Jayaweera et al., 2015). CIDA price fluctuation formula is given in equation (01).

$$
F=\frac{0.966(V-V n a)}{100} \sum_{\text {All inputs }} \frac{P x\left(I_{x b}-I_{x c}\right)}{I_{x b}}
$$

Where, $\mathrm{V}=$ Valuation of work done for period; Vna = Non-adjustable elements; Px $=$ Input percentage; $\mathrm{I}_{\mathrm{xb}}=$ Base index for input $\mathrm{X}$, published by CIDA; $\mathrm{I}_{\mathrm{xc}}=$ Current index for input $\mathrm{X}$, published by CIDA.

De Mel (2008) detailed that there are some assumptions were made to establish the CIDA formula for minimizing the difficulty and developed it as user-friendly. Mainly two assumptions were made when the formula was established, it should be considered as the inputs are evenly spread in the contract (Mel, 2013) and also the major cost was considered as $90 \%$ of the project value and balance should be minor cost, i.e. the major cost recovered when the work items completed up to $40 \%$ (CIDA, 2008). Also, it was assumed the payment for a price adjustment should be paid on a monthly cumulative basis as a part of the monthly interim payment application to the contractor (Jayalath, 2013).

\subsection{ROAD CONSTRUCTION INDUSTRY}

The infrastructure is vital for the transport of products and ensures business and private travel quality, so the investment needed in infrastructure projects is far higher compared to different tiny building projects (Kaare and Koppel, 2012). Although Sri Lanka's infrastructure was suffered by civil war it has a higher density of roads in South Asia, and the government needs to increase the capacity of roads due to the traffic problems which were encountered while contributing to the maintenance of roads (World Bank, 2016). Due to its long project duration and high investment of money, road construction faces the risks due to price fluctuation. So, it will surely affect the economy of Sri Lanka significantly.

\section{RESEARCH METHODOLOGY}

A mixed base approach was carried out to attain the research aim which is to. Initially, a deep comprehensive study of literature survey was carried out through previous research papers, government and non-government publications, journals and articles, conference proceedings and internet data to review the price fluctuation concept and the methods of price fluctuation reclamation and the status of road construction in Sri Lanka. Interview guidelines and questionnaires were prepared for data collection. Qualitative data were collected via interviews and the quantitative data were collected via questionnaires to identify and analyse the factors affecting the formula in road construction, classify the issues when applying the formula in road construction projects and to find the limitations with the calculation using the formula in road construction. Data was collected from experts who are working in the construction industry. The analysis of the collected data 
was done by two different methods. The quantitative data were analyzed through SPSS software and the qualitative data were analyzed through QDA Miner Lite software to develop a framework to minimise future problems of using the formula in road construction projects.

\section{RESULTS AND DISCUSSION}

\subsection{INTERVIEW SURVEY ANALYSIS AND DISCUSSION}

After analyzing the received results, it was found that the CIDA formula and FIDIC formula for price fluctuation are a widely used method in the road construction industry. Normally the FIDIC formula is used for foreign-funded projects at the same time the CIDA formula is used for local projects. There are some advantages of Using CIDA formula for price fluctuation in construction contracts. Those are,

- Easy, availability, user-friendly and it should be applicable for any type of contract

- Easy to maintain the cost of construction

- Both client and consultant are benefited

- Simple and less time allocation for calculation

- Some assumptions were made in order to establish the price fluctuation formula which are making the calculation process of the formula easy

\subsubsection{Difficulties faced During Calculation Process}

Receiving the CIDA bulletin lately is the main difficulty which was faced by the industry. Because it will make the calculation process slow. And the calculation of input percentage is a difficult process and tedious task. Because it requires more time and more documents to calculate that. The items like Tar, Gravel want to be included in the CIDA bulletin. Those materials are major materials that are used in road construction projects. The usage is higher than other materials. At the same time, heavy machinery should be categorized in the bulletin. There are one price indices for all heavy machinery. But the rates between machinery have a huge difference. So, the price fluctuation can be varied.

\subsubsection{Factors Affecting CIDA Formula}

Fluctuation in material prices is the main factor that is affecting the usage of CIDA formula in road projects. Materials like Asphalt products (Bitumen, Tar), Metal and other major material prices are increasing rapidly. Further, using a large number of precast structures for construction of roads, increase in heavy vehicle usage, road furniture, increase in skilled labor requirements, usage of gravel, etc. Those new aspects are affecting the calculation process of price fluctuation using the CIDA formula. Other than normal assumptions further, they are not considering the CPI (consumer price index), Provisional sum items not considered for the calculation and there are some other assumption like Input indices as per contract, not considering high taxes on imported material, work considered for the IPA (Interim Payment Application) within its month are followed when using the CIDA formula. Highway schedule of rates (HSR) and CIDA bulletin are the main norms used for calculation. The main issues with the Bulletin are, receiving the bulletin lately and the accuracy of Indices is low due to the location changes. The issue in HSR is, the HSR is not updated. 


\subsubsection{Suggestions for Identified Problems}

- Prepare the bulletin in location-wise,

- Receive the bulletin in time

- Increase the accuracy of the bulletin by considering location,

- Separate the indices for every heavy machinery,

- Insert the identified inputs in the bulletin

\subsection{QUESTIONNAIRE SURVEY ANALYSIS AND DISCUSSION}

Pre-determined questionnaires with 10 optional close-ended questions were provided among 15 practitioners in the industry to collect quantitative data and full freedom was provided to them to select their answer with their experience. All the data collected through the questionnaire were updated in the SPSS software and the results were produced in bar charts. The following findings were revealed from the analysis.

CIDA and the FIDIC formulas are suitable for the calculation of Price fluctuation amount in road construction (see Figure 1).

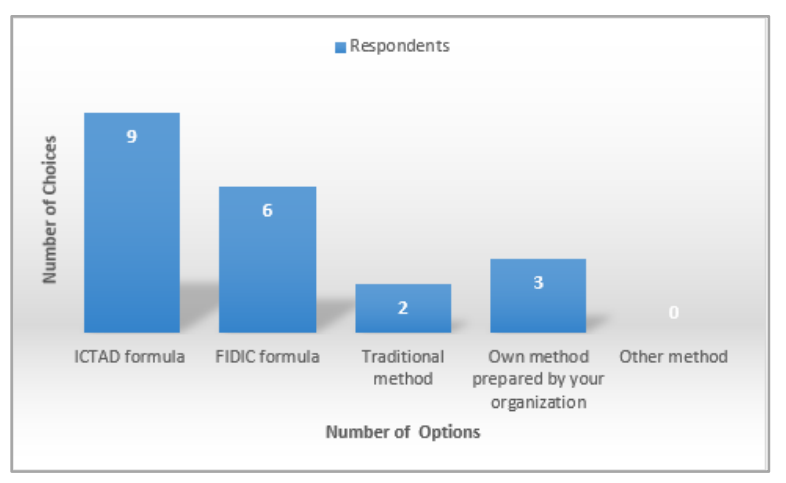

Figure 1: Analysis of questionnaires

But, there should be considerable changes in price indices, total input percentage, coefficient (0.966) to make the CIDA formula more accurate when it is used for road construction. It is important to recall that a cost index measures the price movement for some objects over time and/or location using a series of values.

CIDA suggested a method for input percentage calculation is more suitable for price fluctuation calculation by using the CIDA formula. But some professionals are doing that by using past projects and sometimes in their own experience. Better to maintain input percentage at $90 \%$ (refer Figure 2). But sometimes it may be increased according to the contribution of materials. Fuel and bitumen have a high impact on the price fluctuation amount due to the fluctuation in the price of Petroleum. 


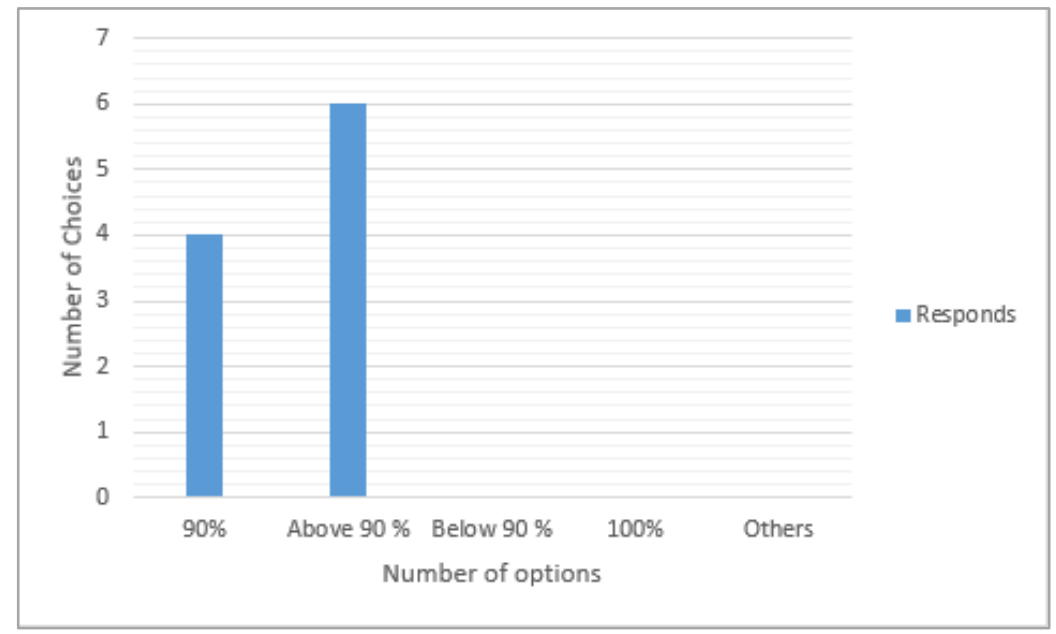

Figure 2: Analysis of suitable input percentage

Materials are not uniformly distributed throughout the construction period. Because the contribution of input material is high in wearing course and finishing course and sometimes in other construction works of roads (refer Figure 3).

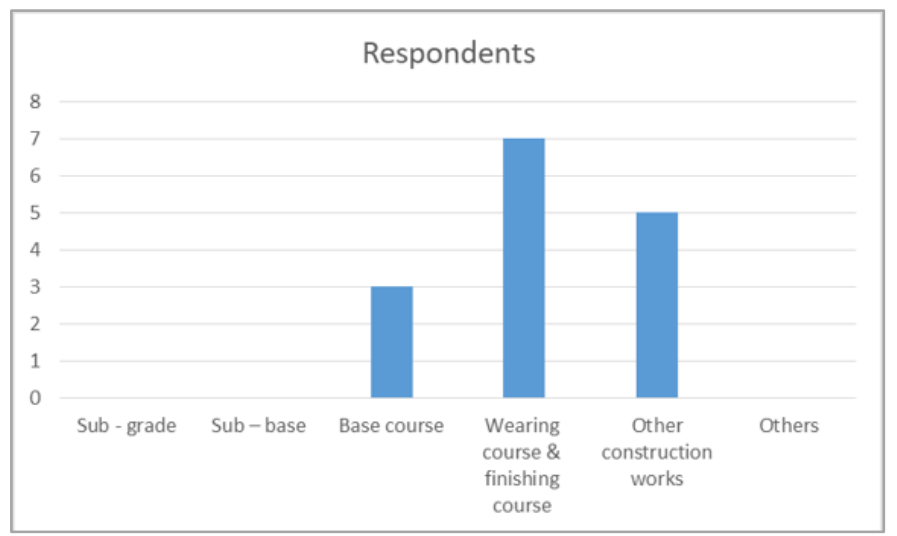

Figure 3: Analysis of material distribution through construction

Using the CIDA formula in fixed contracts can be made a high risk for the client due to the fixed amount. The risk is high when the formula loses the effectiveness in the unit price contract.

\section{SUMMARY AND CONCLUSIONS}

This study was focused on to find out the factors affect the CIDA price fluctuation formula in road construction projects and to identify the appropriate use of the CIDA price fluctuation formula for road construction. Throughout this study, it was found that normally in the road construction industry they are using CIDA formula than other calculation methods like FIDIC formula. But, FIDIC formula also in practice. That means nowadays in Sri Lanka most of the road construction projects are funded by ADB and other foreign countries. So, they have to follow the FIDIC formula for the construction projects. But from the results were identified that they mostly following the CIDA formula because of the easy, simple and less time consuming and further advantages. As well as there are some considerations and considerable changes want to be there before using the formula as the results of the respondents' opinion. Without those changes, the 
CIDA formula is not appropriate to use in road construction. Therefore, improvement efforts need to be taken to improve the current condition.

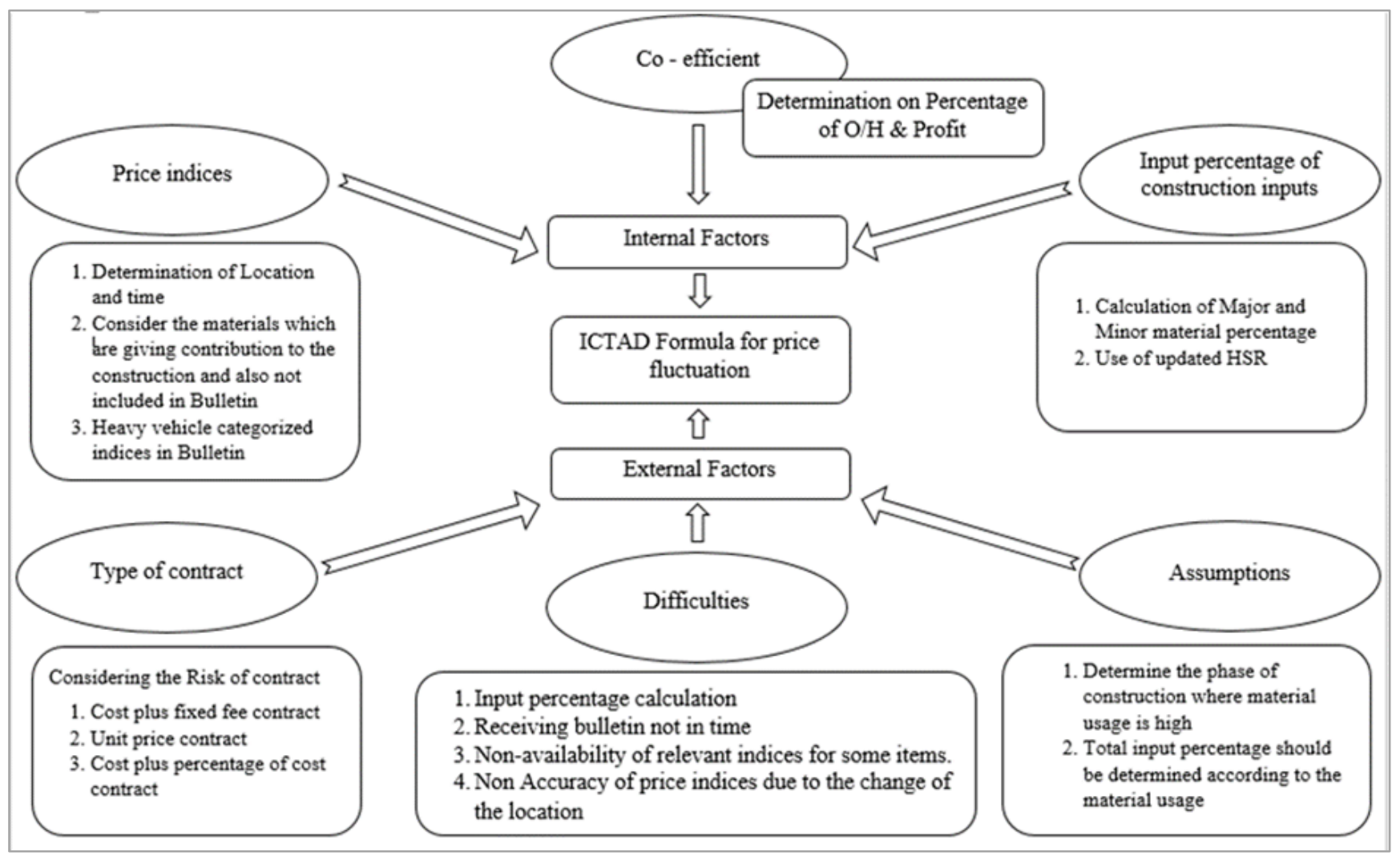

Figure 4: Summary of significant factors affecting CIDA formula in road construction

\section{REFERENCES}

Asian Development Bank 2018. Price adjustment guidance note on procurement. Available from https:// www.adb.org / sites/ default/ files/ procurement-price-adjustment.pdf.

Construction industry council 2011, Guidelines on contract price fluctuation system, Hong Kong, CIC.

Dawood, N., Yasuhara, T., Usuda, Y., Matsuda, C. and Sawada, A., 2001. Analysis of cost escalation and risk assessment of infrastructure project. In Proceedings of $17^{\text {th }}$ Annual ARCOM Conference, Salford, UK, pp.835-844.

De Mel, J., 2009. Basic Concepts and Derivation of CIDA Formula and Introduction of CIDA Formula. CIDA price fluctuation formula. Colombo: Institute for Construction Training and Development.

Dilshani, L. D. T. and Disaratna, P. A. P. V. D. S., 2014. A Review of CIDA Standard Bidding Document 02 (2007) for Major Contracts. In Proceedings of the Third World Construction Symposium 2014: Sustainability and Development in Built Environment (pp.36-46). Colombo: Ceylon Institute of Builders, Sri Lanka.

Douglas, G., 2010. Agriculture, Roads, and Economic Development in Uganda, NBER Working Paper No. 15863, and Issued in April 2010, NBER program: PE-PR.

Hanna, A.S. and Blair, A.N., 1993. A Rational Method for the Treatment of Escalation in Construction Costs. Organisation and Management of Construction the Way Forward, 1(3), pp.1415-1425.

Institute for Construction Training and Development (CIDA), 2007. Standard Bidding Document Procurement of Works-Major Contracts. Colombo: Institute for Construction Training and Development, (CIDA/SBD/02).

Institute for Construction Training and Development (CIDA), 2008, ICTAD formula method for adjustments to contract price due to fluctuation in prices, Colombo, Institute for Construction Training and Development. 
Jayalath, C., 2013. Arguing Construction Claims. Colombo: S Godage and Brothers Pvt Ltd.

Jayasinghe, S. A. Y. B., Alahakoon, C. S., and Wijewardena, L. S. S., 2015. Sensitivity of the CIDA Price Fluctuation Formula Procedure for the True Material Price Fluctuations in Construction Industry. Journal of Engineering and Technology of the Open University of Sri Lanka (JET-OUSL), 3(1), pp.1940.

Jayaweera, S.C., Perera, B.A.K.S., and Jayasinghe, S.J.A.R.S., 2015. Applicability of CIDA price fluctuation formula for Government funded intelligent building projects. Department of Building Economics, University of Moratuwa, Sri Lanka.

Kaare, K. K. and Koppel, O., 2012. Improving the road construction supply chain by developing a national level performance measuring system. International Journal of Social and Human Sciences, 6(2), pp.225-231

Kaliba, C., Muya, M. and Mumba, K., 2009. Cost escalation and schedule delays in road construction projects in Zambia. International journal of project management, 27(5), pp.522-531.

Lioudis, N.K., 2018. What causes oil prices to fluctuate? Available from https:// www.investopedia.com/ ask/answers/ 012715/what-causes-oil-prices fluctuate.asp.

Liyanage, B., 2005. Examination of Price Fluctuation Reimbursement by Simplified CIDA Formula. Unpublished Dissertation (B.Sc.). Department of Building Economics, University of Moratuwa, Sri Lanka.

Macdonald, R., 2013. Cost risk mitigation on construction projects, University of Alabama, Tuscaloosa, Alabama, August 2013.

Mel, J.D., 2013, Basic concepts and logical approach of CIDA formula, Colombo, CIDA.

Mishra, A.K. and Regmi, U., 2017. Effects of Price Fluctuation on the Financial Capacity of "Class A" Contractors. International Journal of Creative Research Thoughts, 5(4), pp.1920-1937.

Moynihan, G.P., Al-Zarrad, M.A., 2015. Application of Hedging Principles to Construction Material Cost Risk Mitigation in Construction Projects. International Journal of Construction Engineering and Management, 4(5), pp.180-190.

National Procurement Agency, 2006, January. Procurement Guideline 2006: Good and Works [online]. Colombo: Department of Government Printing. Available from: www.treasury.gov.lk // ProcurementGuidelines2006 _ amded12June.pdf [Accessed 20 April 2014].

Nwuba, C., 2004. An analysis of housing construction costs trends in Nigeria, 1986-2002. The Quantity Surveyor, 47, pp.4-9

PECI, 2009. Standard Procedure and Formula for Price Adjustment. Pakistan Engineering Council, Islamabad.

Raniga, P., 2015. Cost Escalation in Road and Rail Construction Projects - NSW Experience. In Proceedings of Australasian Transport Research Forum 2015.

Rodriguez, J., 2018. How to Include Price Escalation Clauses in a Construction Contract. Retrieved from https:// www. thebalancesmb. com/ escalation- clause- construction- contracting- 844531

Sendooran, B., 2005. Impact of Oil Price in Construction Industry. Unpublished Dissertation (B.Sc.). Department of Building Economics, University of Moratuwa, Sri Lanka

Silva, L., 2011. Forecasting of Cost Escalations in Post Disaster Construction with Tsunami Reconstruction in Sri Lanka. Built-Environment Sri Lanka, 09(01-02), pp.56-63.

Suraweera, E.H., 2001. Inflation and Dealing with Price Fluctuation. Unpublished Dissertation (B.Sc.). Department of Building Economics, University of Moratuwa, Sri Lanka.

World Bank, 2016. 10 Years of Better Roads in Sri Lanka. Retrieved from, http://www.worldbank.org/en/news/feature/2016/05/05/10-years-of-better-roads-in-sri lanka 